Research Article

\title{
Apparatus Developments of Ultrasonic Vibration-Assisted Microabrasive Waterjet Polishing
}

\author{
Rongguo Hou $(\mathbb{D}$, Tao Wang $(\mathbb{D}$, Zhe Lv, and Yansen Feng \\ College of Mechanical Engineering, Shandong University of Technology, 255000 Zibo, China \\ Correspondence should be addressed to Rongguo Hou; hourongguo212@163.com
}

Received 8 October 2018; Revised 31 October 2018; Accepted 12 November 2018; Published 2 December 2018

Academic Editor: Hongtao Zhu

Copyright ( 2018 Rongguo Hou et al. This is an open access article distributed under the Creative Commons Attribution License, which permits unrestricted use, distribution, and reproduction in any medium, provided the original work is properly cited.

\begin{abstract}
The experiment apparatus of ultrasonic vibration-assisted microabrasive waterjet polishing is developed. The simulation model of ultrasonic nozzle is analyzed with the help of ANSYS software. The simulation result shows that the ultrasonic vibration leads to a good result that the maximum frequency with the value of $20908 \mathrm{~Hz}$ is obtained at the outlet of ultrasonic nozzle, and the vibration type is axial mode. Then the vibration frequency and amplitude of the developed experiment apparatus are tested using the ultrasonic transducer impedance analyzer and the laser displacement sensor. The measured result indicates that the vibration frequency is $19099 \mathrm{~Hz}$ and the amplitude is $22 \mu \mathrm{m}$, which means the experiment apparatus is well developed and satisfies the work requirements. The verifying experimental result shows that the ultrasonic vibration helps to enhance the machining ability of the abrasive waterjet, and the removal material volume and erosion depth are increased obviously.
\end{abstract}

\section{Introduction}

As one of the fastest growing nonconventional machining processes, abrasive waterjet (AWJ) plays an important role in many manufacturing applications such as cutting [1], surface cleaning [2], and surface treatment [3]. In order to achieve ultraprecision polishing glass, vibration has been introduced in the polishing field. Although in some research the type and production method of vibration are different, the assisted objects are all conventional mechanical tools. For example, the vibration could be produced by a vibrator made of a giant magnetostrictive material, and it belongs to mechanical vibration $[4,5]$. Another type of ultrasonic vibration produced by the ultrasonic vibrator is also used to assist the diamond wheel and improve machining efficiency and precision [6]. There is no doubt that in these research studies, the vibration brings good effect on polishing results, but this conventional grinding tool inevitably results in severe thermal damage to workpiece $[7,8]$. However, AWJ as a cold-working process has certain unique advantages, such as no heat deformation, less machining force exertion, and friendly environment $[9,10]$. Also, entrained with abrasive particles, AWJ is able to machine a variety of materials ranging from soft to hard materials [11]. Because of very low machining efficiency of AWJ, there are a wide range of parameters needed to be optimized such as system pressure, abrasive flow rate, distance of the standoff, moving velocity, etc $[12,13]$. Meanwhile, relevant research studies $[14,15]$ indicate that the ultrasonic vibration has a positive influence on polishing results by improving the kinetic energy of the abrasive waterjet. Based on the abovementioned analysis, this work aims to develop the experiment apparatus of the ultrasonic vibration-assisted microabrasive waterjet polishing and have the AWJ technology and ultrasonic vibration perfectly combined. The simulation analysis, parameters testing, and verifying test are as the primary means to obtain the feasible experiment apparatus.

\section{Working Principle and Composition of the Apparatus}

The working principle of the ultrasonic vibration-assisted microabrasive waterjet is shown in Figure 1. The ultrasonic vibration generated by the transducer is further enlarged by the amplitude horn, and the maximal amplitude occurs at the nozzle outlet where the best combining effect of highpressure liquid energy and ultrasonic vibration energy is obtained. With the abrasive waterjet injecting from the 


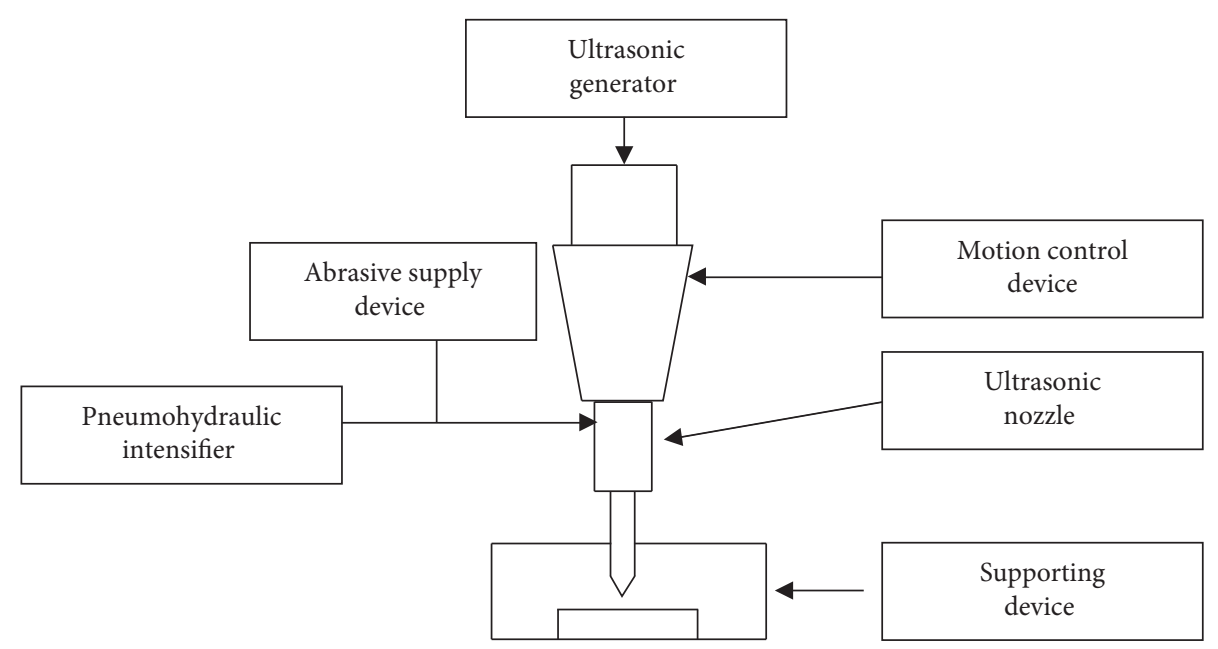

FIgURE 1: The device of ultrasonic vibration-assisted abrasive waterjet.

nozzle, the total combining energy is converted into the impacting kinetic energy. As a consequence of the addition of ultrasonic vibration energy, the impacting kinetic energy of the abrasive waterjet is improved significantly, which leads to more damages to the workpiece.

In order to improve the working performance of ultrasonic nozzle, a combination of horn-type structure is proposed creatively so as to ensure that the maximum vibration amplification factor satisfies the work requirements. This newly designed horn consists of two halfwavelength horns: the promote part and the output part. The cascade horn is obtained after a plurality of single horn is connected end to end. The structure of ultrasonic nozzle is shown in Figure 2. Because the horn needs to be drilled, threaded, and corrosion-resistant, the titanium alloy was used. The properties of titanium alloy are shown in Table 1.

Figure 3 shows the experiment apparatus of the ultrasonic vibration-assisted microabrasive waterjet. This experiment apparatus mainly consists of the ultrasonic generator, the transducer, and the amplitude horn. In order to obtain the required working pressure and supply energy to the testing system, the hydraulic intensifier is employed to increase the pressure of low-pressure water by using highpressure gas (it can provide the system with the pressure from 0 to $70 \mathrm{MPa}$ ); the abrasive supply device (the mesh of abrasive is 240\#) driven by low-pressure gas (the drive pressure is $0.8 \mathrm{MPa}$ ) is used to transport the abrasive to the nozzle; the motion-control device is used to drive the moving device of the ultrasonic-assisted waterjet nozzle so as to obtain the desired shape; the supporting recovery device is used to achieve the positioning and clamping of workpiece as well as the collecting of residues.

\section{The Simulation of the UMAWJ Nozzle}

3.1. The Setup of Simulation Model. According to the work requirements, the working frequency should be about $20 \mathrm{kHz}$ and the amplitude generated at the outlet of ultrasonic nozzle should be about $20 \mu \mathrm{m}$. The main parameters of the ultrasonic nozzle are shown in Table 2. Figure 4 is the physical model of modal analysis. Figure 5 is the mesh model of modal analysis.

Due to the merits of plasticity, stress stiffening, large deflection, and large strain, the type of Solid45 element with 8 nodes was used, and the version of ANSYS is 12.0. The block Lanczos was used as the extraction methods, and the frequency search interval was set between 10 and $20 \mathrm{kHz}$. In the construction process of simulation model, the influence of thread connection was not taken into account so as to simplify the analysis. In other words, the promote part and the output part are considered as a whole instead of individual parts. Since the zero displacement constraint is the only effective load for the modal analysis, the boundary condition is displacement constraint, that is, the displacement in the $X, Y$, and $Z$ direction is zero.

3.2. The Simulation Result and Analysis. In the analysis settings, the item of "max modes to find" was set at 8 . After the calculation, the corresponding 8 subitems of "total deformation" were applied to the solution item; after the evaluation of all results, 8 vibration modes were extracted, and the natural frequency of the nozzle model was obtained from Figure 6.

According to Figure 6, it indicates that the frequency shown in Figure 6(b) is axial, while the others are torsional and swing, and its value is $20908 \mathrm{~Hz}$, which is close to the required working frequency of $20 \mathrm{kHz}$. Therefore, it is certain that the designed amplitude horn meets the work requirements totally, and the designed parameters of the ultrasonic nozzle do not need to be adjusted.

The reason why there is error between the calculated value of $20908 \mathrm{~Hz}$ and the required working frequency of $20 \mathrm{kHz}$ is that the formula for amplitude horn design is an empirical formula, and the optimization problem is involved as well. Therefore, the error is inevitable. In addition, the related experimental parameters such as elastic modulus, Poisson ratio, and density and the mesh density of ANSYS software also play an important role in the generation of error. 


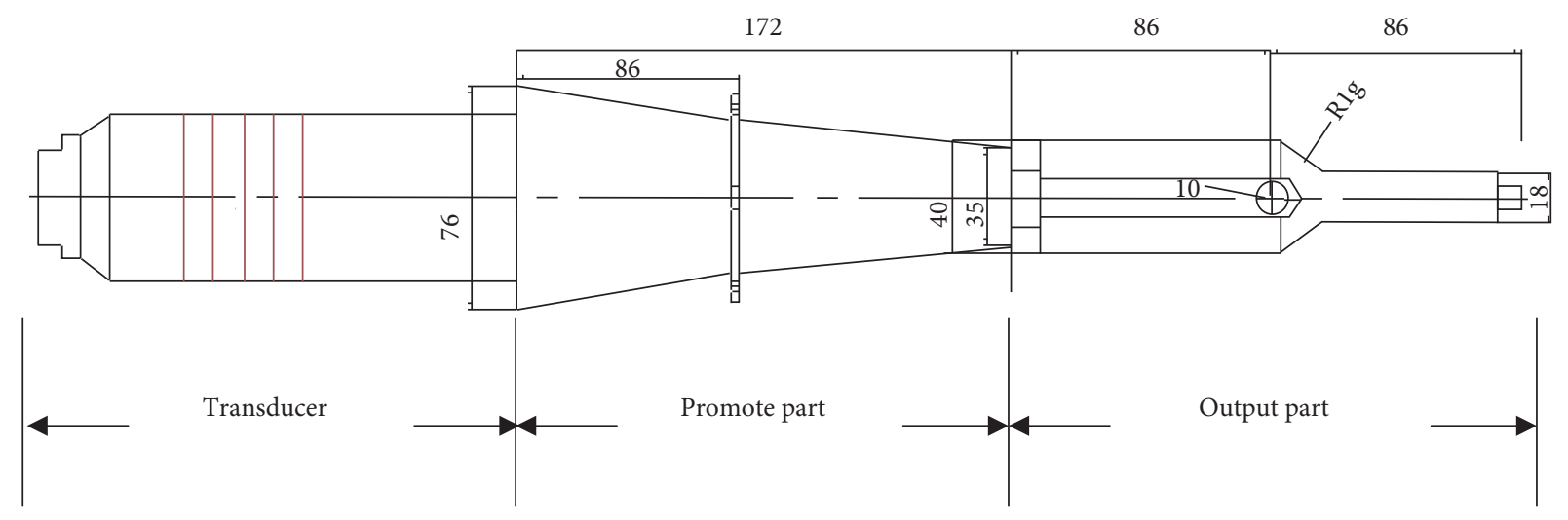

Figure 2: The structure of ultrasonic nozzle.

TABLE 1: The properties of titanium alloy.

\begin{tabular}{lccr}
\hline Density $\left(\mathrm{kg} / \mathrm{m}^{3}\right)$ & Young's modulus $10^{10}\left(\mathrm{~N} / \mathrm{m}^{2}\right)$ & Tensile strength $10^{7}\left(\mathrm{~N} / \mathrm{m}^{2}\right)$ & Longitudinal wave velocity $(\mathrm{m} / \mathrm{s})$ \\
\hline 4500 & 12.07 & $90-108$ & 4920 \\
\hline
\end{tabular}

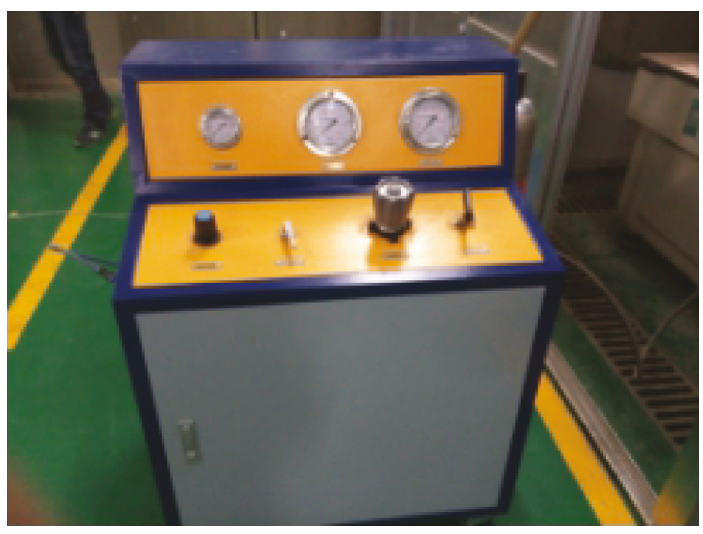

(a)

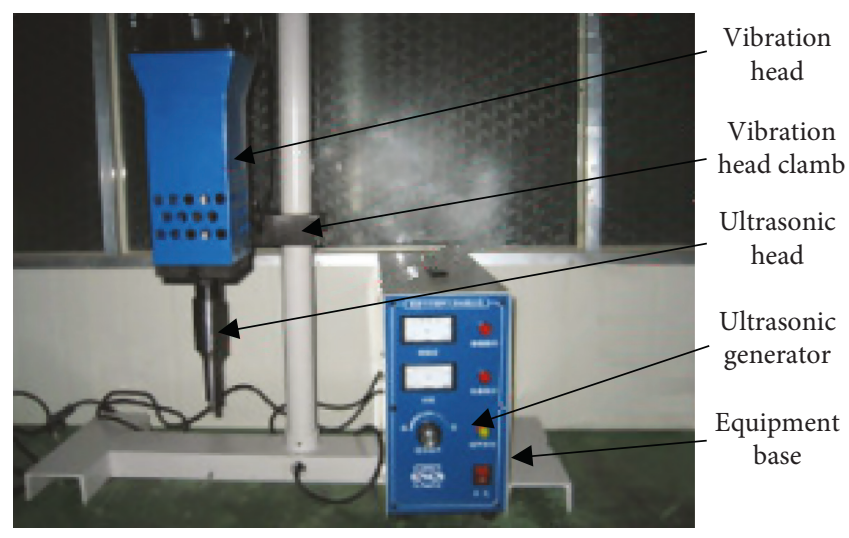

(b)

FIgURE 3: The apparatus of ultrasonic vibration-assisted abrasive waterjet. (a) The pneumohydraulic intensifier. (b) The device of ultrasonic vibration-assisted waterjet.

TABLE 2: The main parameters of ultrasonic nozzle.

\begin{tabular}{lcccccrr}
\hline $\begin{array}{l}\text { Vibration } \\
\text { frequency }(\mathrm{kHz})\end{array}$ & $\begin{array}{c}\text { Transducer } \\
\text { amplitude }(\mu \mathrm{m})\end{array}$ & Amplification & $\begin{array}{c}\text { Large } \\
\text { diameter }(\mathrm{mm})\end{array}$ & $\begin{array}{c}\text { Pore } \\
\text { size }(\mathrm{mm})\end{array}$ & $\begin{array}{c}\text { Vibration } \\
\text { form }\end{array}$ & $\begin{array}{c}\text { Power } \\
\text { consumption }(\mathrm{kW})\end{array}$ & Wavelength \\
\hline 20 & 2 & 10 & 50 & 1 & Vertical & 1.5 & Half-wavelength \\
\hline
\end{tabular}

\section{The Test of Developed Apparatus Parameters}

Because the parameters, such as frequency and amplitude, are the important bases for the performance evaluation of the developed apparatus, the impedance analyzer of the ultrasonic transducer and the laser displacement sensor are used to measure the vibration frequency and amplitude of the developed apparatus.

\subsection{The Measurement of Frequency}

4.1.1. The Measurement Method. In order to obtain the optimal frequency, the testing result requires no parasitic circle generated inside the admittance circle and low dynamic impedance, and it requires that the resonant frequency should be close to the required working frequency of $20 \mathrm{kHz}$. The quality of the piezoelectric patch can be evaluated from the admittance circle figure and the logarithmic coordinate. If there is delamination or crack generated inside the piezoelectric patch, the logarithmic curve will have many peak values and there will be many small parasitic circles inside the admittance circle. Table 3 shows the main technical indexes. Figure 7 shows the frequency measurement of the ultrasonic nozzle.

4.1.2. The Result and Analysis. According to Figure 8, there is no parasitic circle generated inside the admittance 


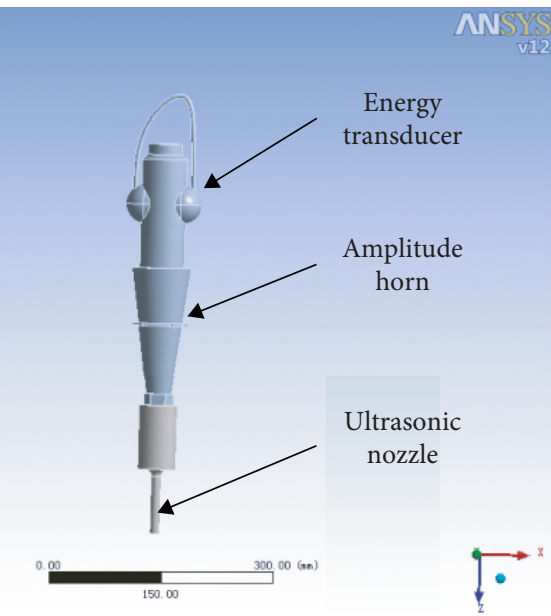

Figure 4: The 3D model.

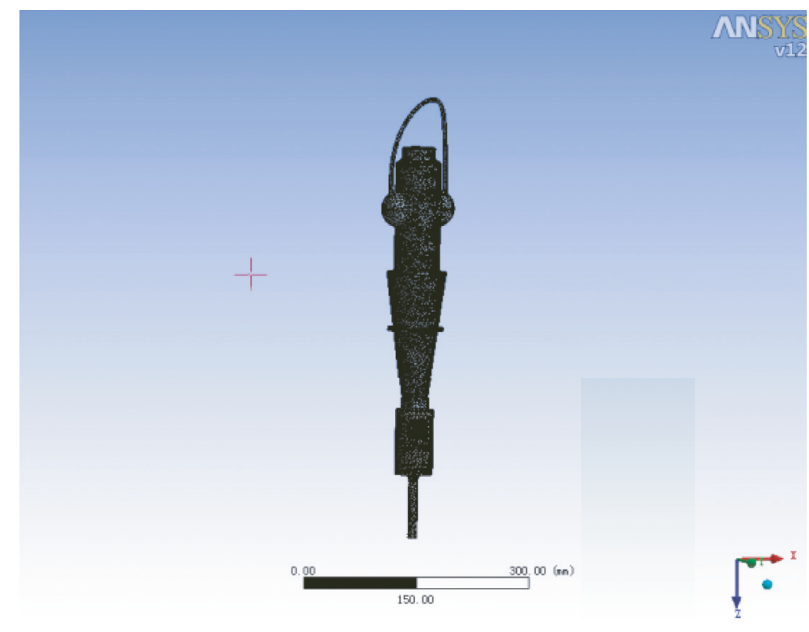

Figure 5: The mesh model.

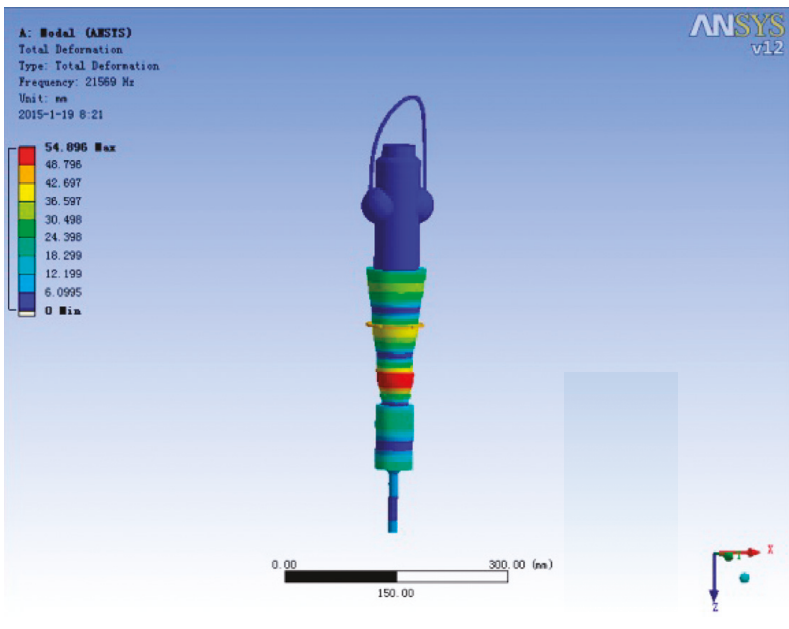

(a)

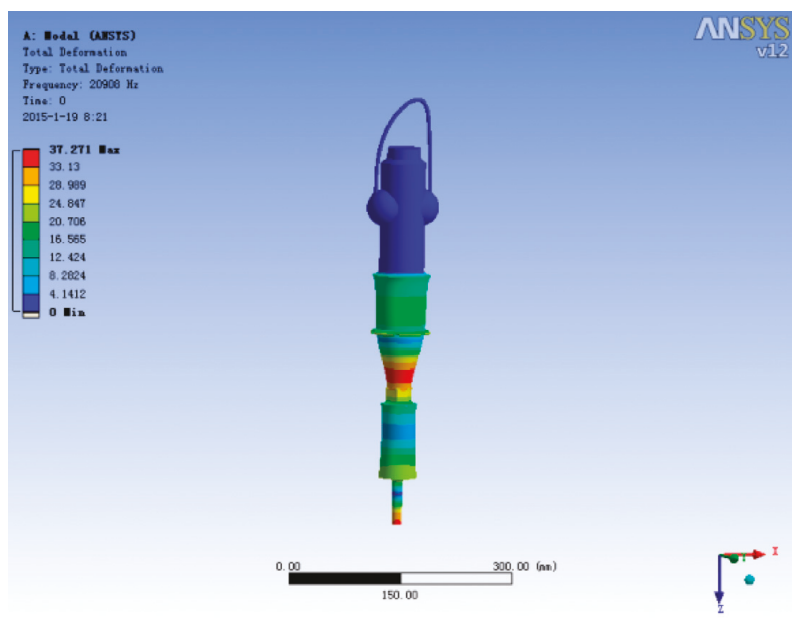

(b)

Figure 6: Continued. 


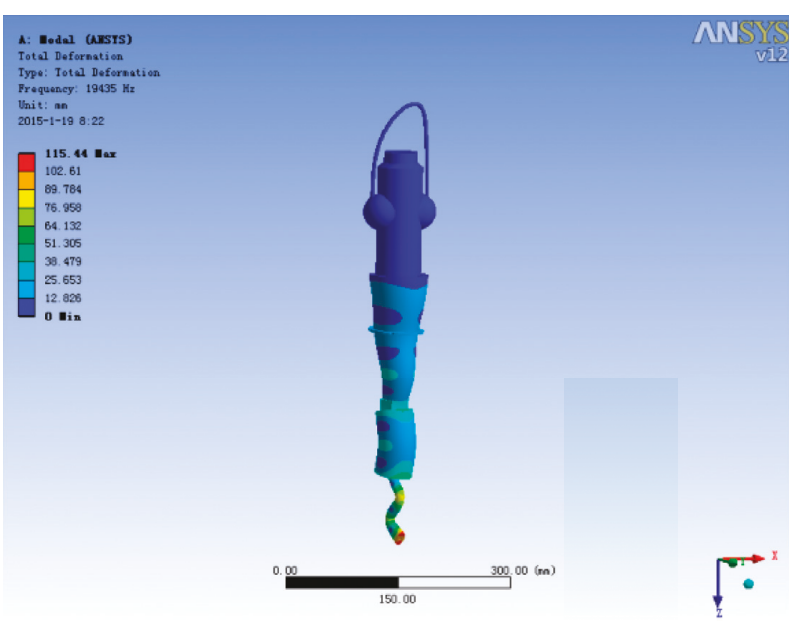

(c)

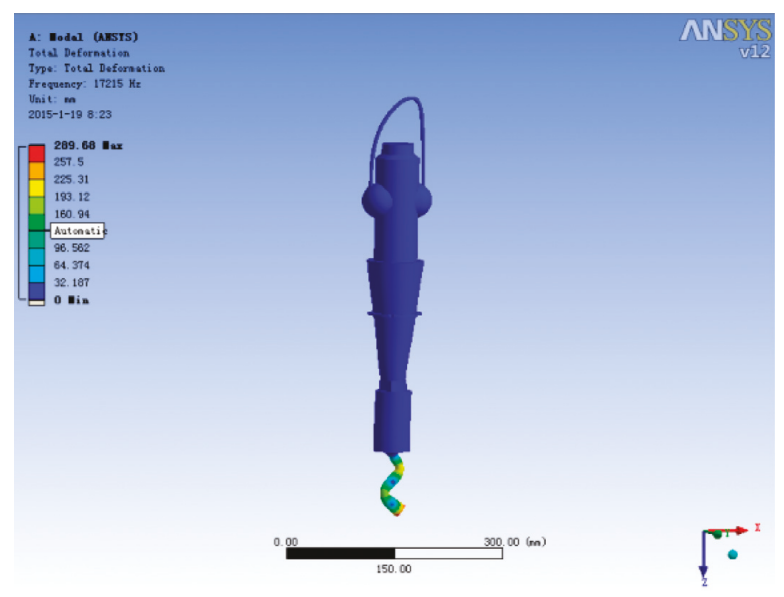

(e)

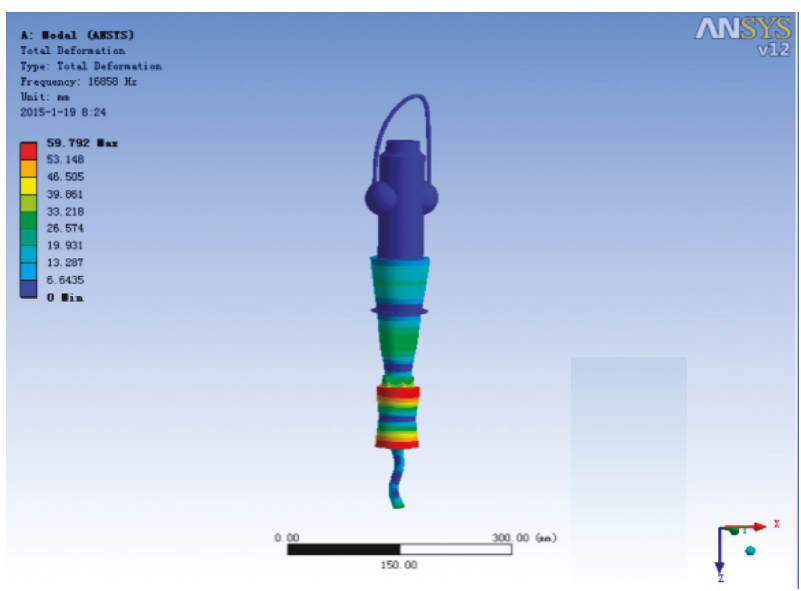

(g)

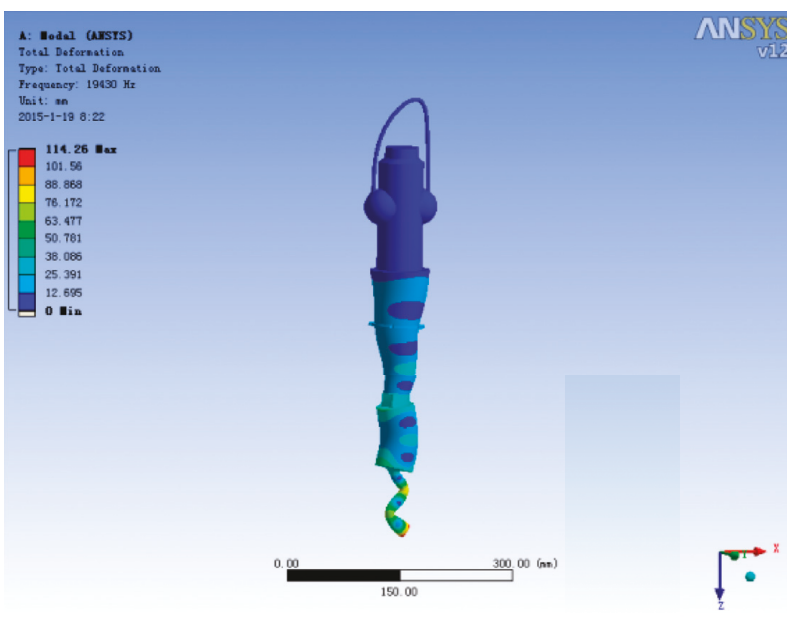

(d)

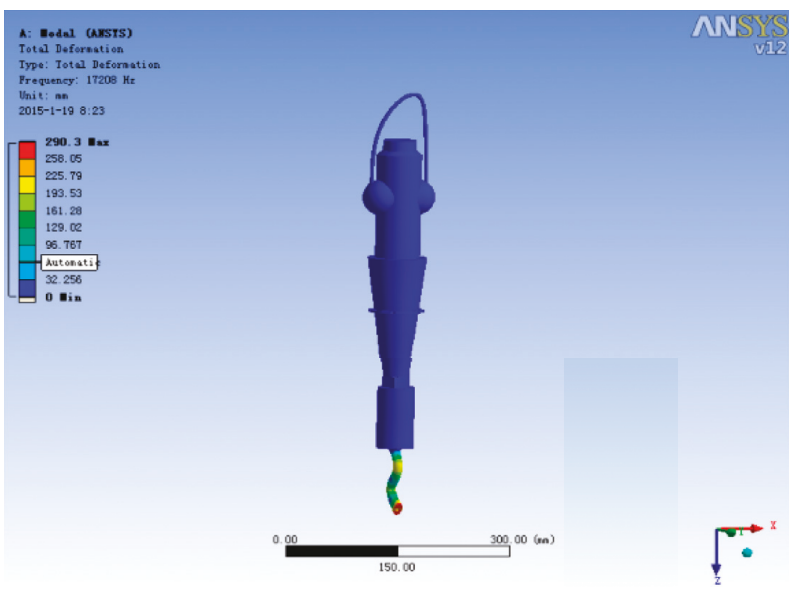

(f)

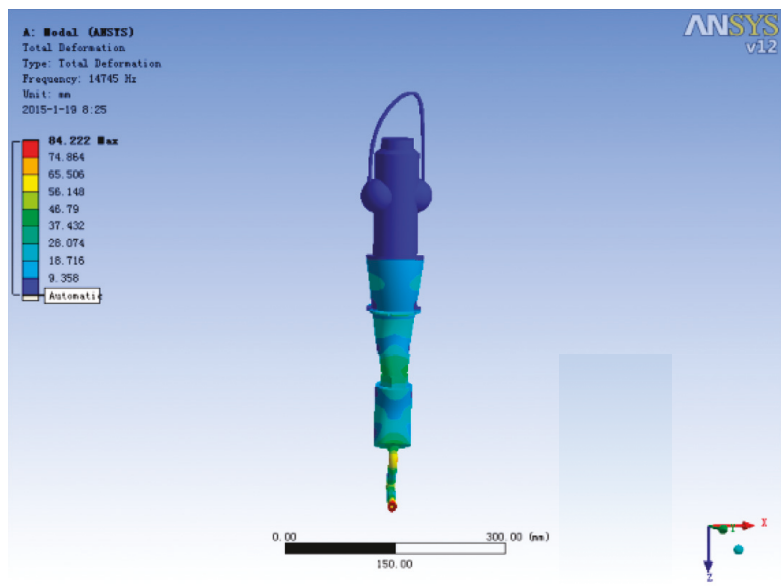

(h)

Figure 6: The nozzle model of ultrasonic waterjet. (a) Frequency of 21569 (vertical). (b) Frequency of 20908 (axial). (c) Frequency of 19435. (d) Frequency of 19430. (e) Frequency of 17215. (f) Frequency of 17208. (g) Frequency of 16858. (h) Frequency of 14745.

circle, and the optimal resonant frequency is $19099 \mathrm{~Hz}$. Comparing the measured frequency of $19099 \mathrm{~Hz}$ with the required working frequency of $20 \mathrm{kHz}$ shows that the difference is within $5 \%$, that is to say, the frequency of the developed ultrasonic nozzle meets the work requirements.

\subsection{The Measurement of Amplitude}

4.2.1. The Measurement Method. Figure 9 shows the measurement device of the amplitude of the ultrasonic nozzle. The main measurement parameter includes the amplitude with the value of $20 \mu \mathrm{m}$. 
TABLE 3: The main technical indexes.

\begin{tabular}{lccccc}
\hline $\begin{array}{l}\text { Working } \\
\text { frequency }(\mathrm{Hz})\end{array}$ & $\begin{array}{c}\text { Impedance } \\
\text { accuracy }\end{array}$ & $\begin{array}{c}\text { Qm } \\
\text { accuracy }\end{array}$ & $\begin{array}{c}\text { Impedance } \\
\text { accuracy }(\mathrm{M} \Omega)\end{array}$ & $\begin{array}{c}\text { Measured } \\
\text { time }(\mathrm{ms})\end{array}$ & Impedance parameter \\
\hline $4 e 1-1.10 e 8$ & $\pm 0.08 \%$ & $\pm 3 \%$ & $3-500$ & 3 & $Z, Y, \theta, R, X, G, B, L, C, D, Q$ \\
\hline
\end{tabular}

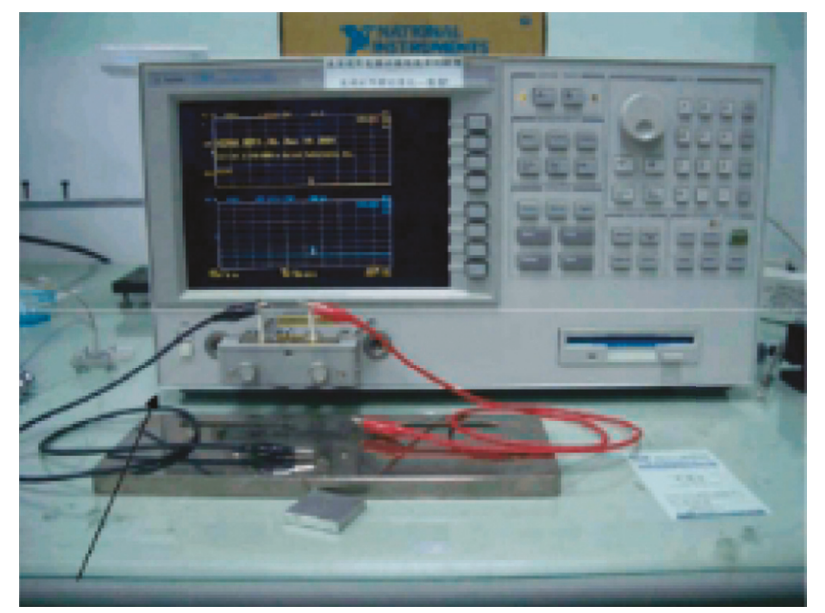

FIGURE 7: The frequency measuring device of the ultrasonic nozzle.

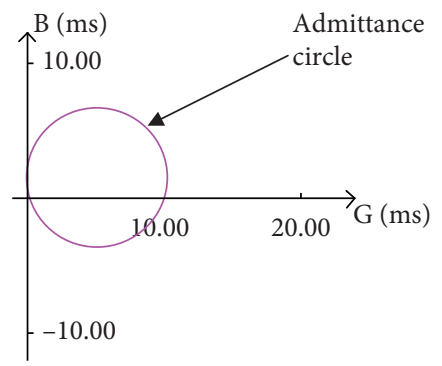

(a)

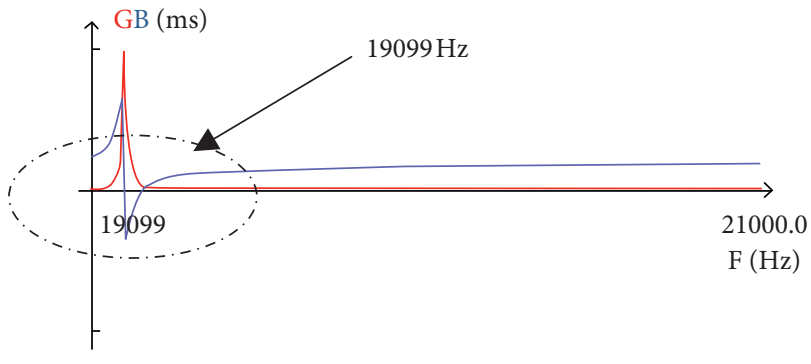

(b)

Figure 8: The measurement result of frequency. (a) Admittance circle. (b) Response frequency.

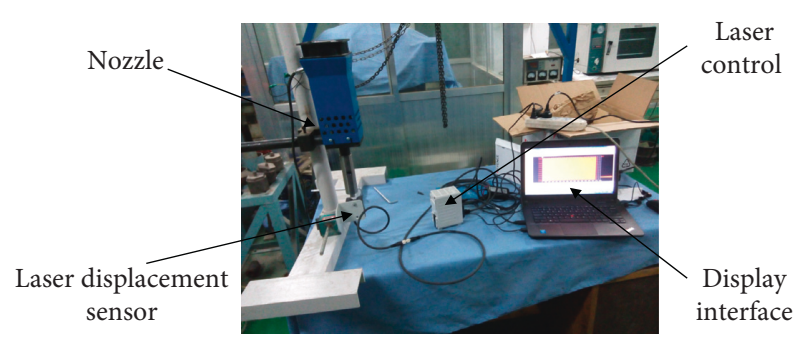

FIGURE 9: The measurement device of amplitude of ultrasonic nozzle.

4.2.2. The Result and Analysis. According to Figure 10, there is fluctuation generated on the nozzle end-face along the axis. The fluctuation range is $44 \mu \mathrm{m}, 34.6 \mu \mathrm{m}$, and $19.57 \mu \mathrm{m}$, which turns into the amplitude with the valve of $22 \mu \mathrm{m}$, $16.8 \mu \mathrm{m}$, and $9.8 \mu \mathrm{m}$. It indicates that the obtained amplitude and the required working amplitude are coincident approximately. In addition, the reason why the amplitude curve in Figures 10(b) and 10(c) is not continuous is that the measurement device was maintained under working condition while the amplitude horn was replaced. Also, it can be found that the fluctuation of amplitude horn 1 is very large; this is mainly because the head of amplitude horn 1 was accidentally destroyed during testing, indicating that the measured position does not belong to the maximum amplitude region.

\section{Verifying Experiment and Its Results}

The quartz glass and green silicon carbide were selected as the workpiece and abrasive separately. The mechanical properties of quartz glass and green silicon carbide are shown in Tables 4 and 5. The quartz glass was eroded in the same point and each eroding time continues for about eight seconds. The experiment parameters are shown in Table 6.

The erosion surface morphology of quartz glass with and without the ultrasonic vibration is shown in Figure 11. It can be noticed that in the absence of ultrasonic vibration, there are fewer erosion pits distributed in the erosion field. After the addition of ultrasonic vibration, not only the number of erosion pits were improved, but the maximum depth of 


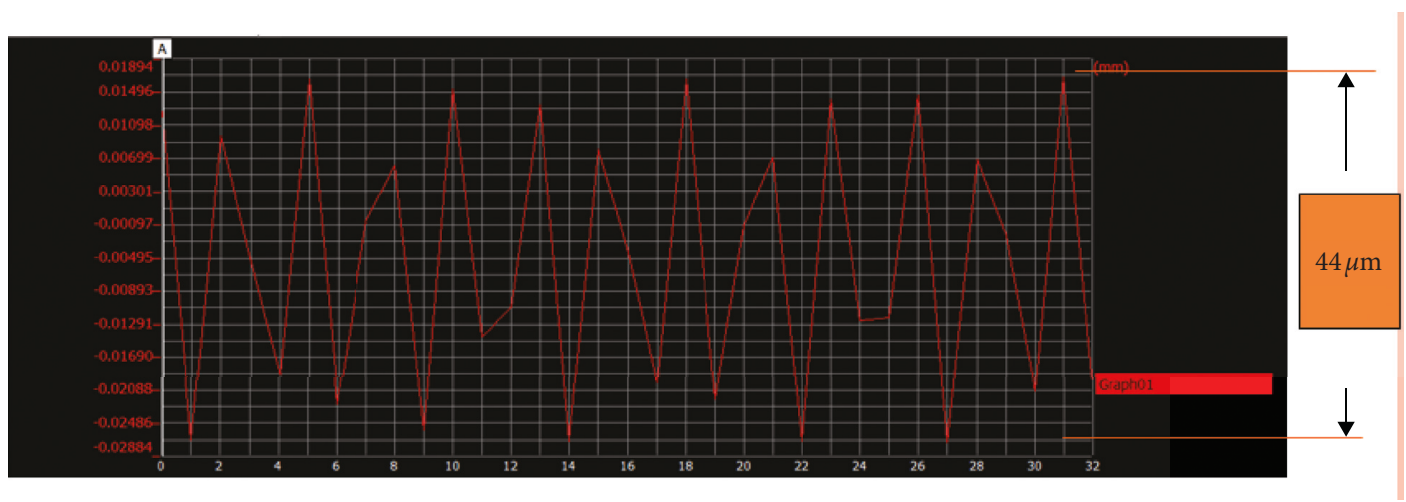

(a)

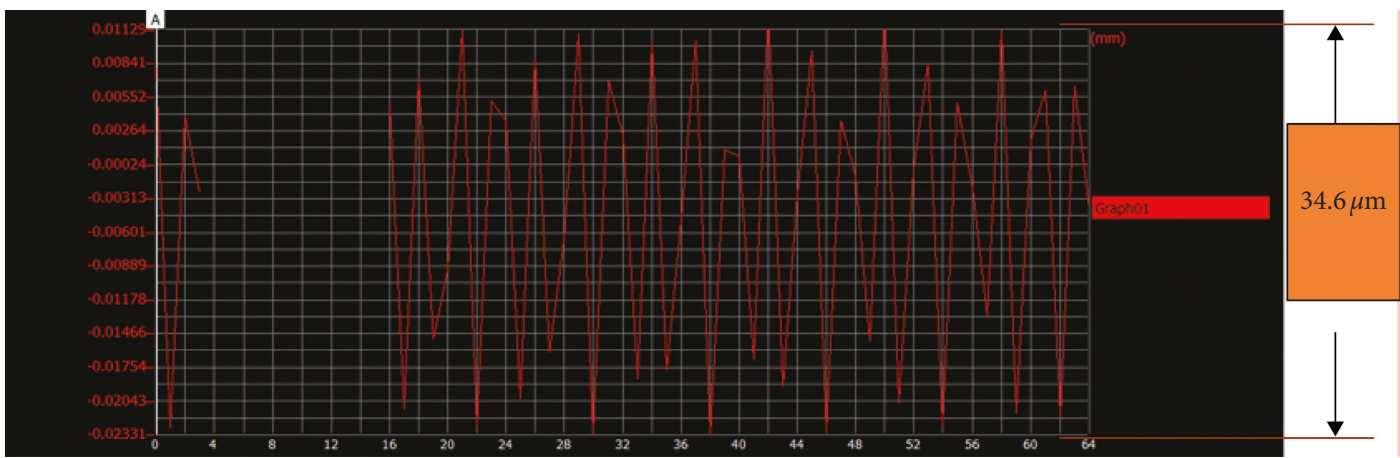

(b)

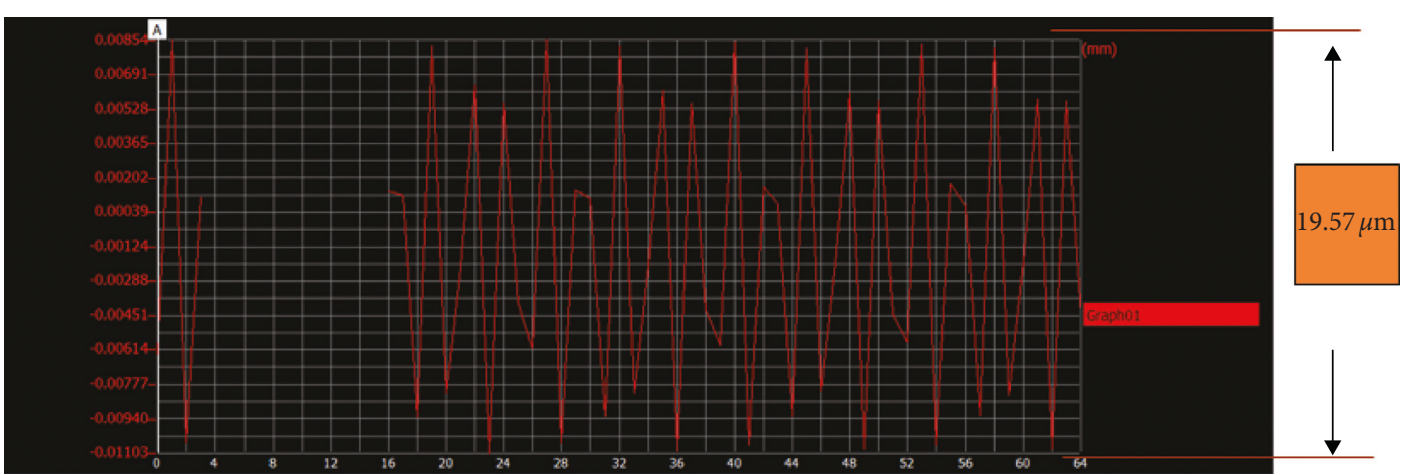

(c)

Figure 10: The measurement result of amplitude. (a) Amplitude horn 1. (b) Amplitude horn 2. (c) Amplitude horn 3.

TABLE 4: Mechanical properties of quartz glass.

\begin{tabular}{lcccccc}
\hline $\begin{array}{l}\text { Density } \\
\left(10^{3} \mathrm{~kg} / \mathrm{m}^{3}\right)\end{array}$ & $\begin{array}{c}\text { Hardness } \\
(\text { Morse })\end{array}$ & $\begin{array}{c}\text { Microhardness } \\
(\mathrm{HV})\end{array}$ & $\begin{array}{c}\text { Tensile strength } \\
(\mathrm{MPa})\end{array}$ & $\begin{array}{c}\text { Compressive } \\
\text { strength (MPa) }\end{array}$ & $\begin{array}{c}\text { Young's } \\
\text { modulus (GPa) }\end{array}$ & $\begin{array}{c}\text { Poisson's } \\
\text { ratio }\end{array}$ \\
\hline 2.2 & $5.5-6.5$ & $8000-9000$ & 50 & 1100 & 72 & 0.17 \\
\hline
\end{tabular}

TABLE 5: Mechanical properties of green silicon carbide.

\begin{tabular}{lcc}
\hline Material & Density $\left(\mathrm{g} / \mathrm{cm}^{3}\right)$ & Mosh hardness scale \\
\hline $\begin{array}{l}\text { Green silicon } \\
\text { carbide }(\mathrm{SiC})\end{array}$ & 3.2 & 9.2 \\
\hline
\end{tabular}

erosion pits and the volume of material removal were increased simultaneously. At the same time, the erosion area and the plastic deforming area were expanded slightly as well.
TABLE 6: The experiment parameters.

\begin{tabular}{lcccc}
\hline $\begin{array}{l}\text { Abrasive } \\
\text { grain } \\
(\mathrm{mesh} / \#)\end{array}$ & $\begin{array}{c}\text { Abrasive } \\
\text { flow rate }(\mathrm{g} / \mathrm{s})\end{array}$ & $\begin{array}{c}\text { Standoff } \\
(\mathrm{mm})\end{array}$ & $\begin{array}{c}\text { System } \\
\text { pressure } \\
(\mathrm{MPa})\end{array}$ & $\begin{array}{c}\text { Amplitude } \\
(\mu \mathrm{m})\end{array}$ \\
\hline 320 & 0.25 & 5 & 20 & 22 \\
\hline
\end{tabular}

Figure 12 is the effect of vibration on the erosion depth and the material removal volume. It is clear from the picture that with the application of vibration, the erosion 


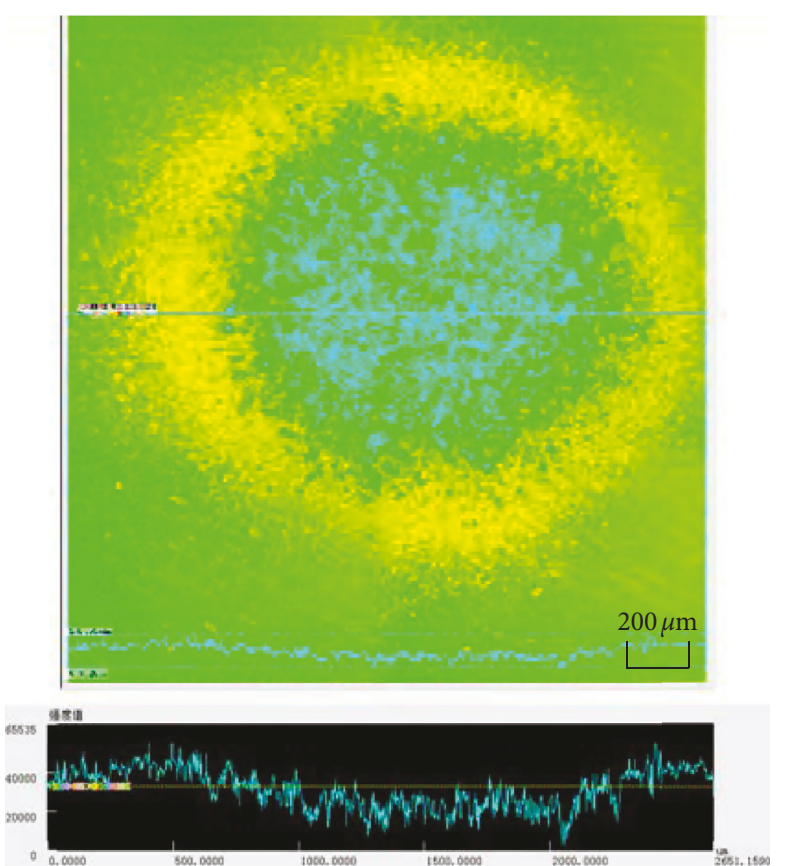

(a)
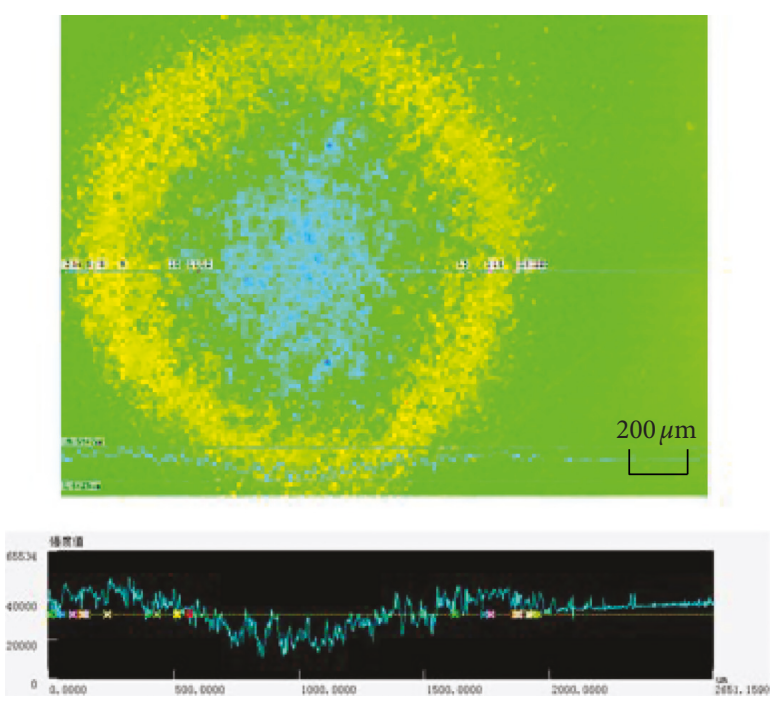

(b)

FIgURE 11: The erosion surface morphology of quartz glass. (a) Without vibration. (b) With vibration.

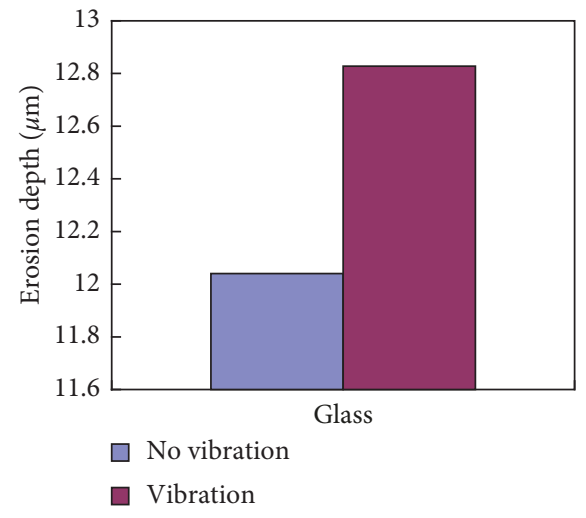

(a)

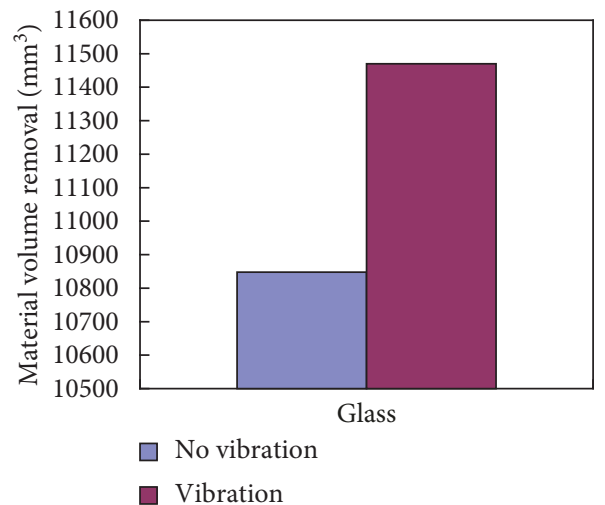

(b)

Figure 12: The erosion depth and material removal amount of quartz glass. (a) Erosion depth. (b) Material removal amount.

depth and the material removal volume maintain the upward trend throughout. Therefore, it comes to the conclusion that the ultrasonic vibration improves the eroding capacity of the abrasive waterjet. Meanwhile, this denotes that the performance of this developed apparatus meets the work requirements.

\section{Conclusions}

The experiment apparatus of the ultrasonic vibrationassisted microabrasive waterjet polishing is developed. The simulation model of ultrasonic nozzle is analyzed by the ANSYS software. The simulation result shows that the vibration type of nozzle is the axial mode, and the frequency value is $20908 \mathrm{~Hz}$, which explains the designed parameters of the ultrasonic nozzle are reasonable. The vibration frequency and amplitude of the developed experiment apparatus are tested with the help of the ultrasonic transducer impedance analyzer and the laser displacement sensor. The measured result indicates that the vibration frequency is $19099 \mathrm{~Hz}$ and the amplitude is $22 \mu \mathrm{m}$, which means the experiment apparatus is well developed and satisfies the work requirements. The polishing experiment on quartz glass is carried out, and the experiment results reflect that the addition of ultrasonic vibration obviously improves the erosion depth and the removal material volume, which means the ultrasonic vibration enhances the machining ability of the microabrasive waterjet greatly. 


\section{Data Availability}

The data used to support the findings of this study are available from the corresponding author upon request.

\section{Conflicts of Interest}

The authors declare that they have no conflicts of interest.

\section{Acknowledgments}

This work is financially supported by the National Natural Science Foundation of China (51405274) and the Development of Young Teachers Program of Shandong University of Technology.

\section{References}

[1] J. Song, Y. Guan, H. Zhao, and Y. Sun, "Experimental study on cutting depth of hard alloy by abrasive water jet," Diamond and Abrasives Engineering, vol. 36, pp. 55-59, 2016.

[2] K. Cao, Q. C. Zhang, Z. L. Xu, and W. H. Li, "Application of abrasive water jet cleaning technique," Cleaning World, vol. 25 , pp. $8-11,2009$.

[3] Y. Song, D. Song, and W. Zhang, "Study on surface quality of stainless steel workpiece polished by abrasive water jet," Electromachining \& Mould, vol. 6, pp. 49-52, 2016.

[4] J. Guo, S. Y. Morita, M. Hara, Y. Yamagata, and T. Higuchi, "Ultra-precision finishing of micro-aspheric mold using a magnetostrictive vibrating polisher," CIRP Annals, vol. 61, no. 1, pp. 371-374, 2012.

[5] J. Guo, H. Suzuki, and T. Higuchi, "Development of micro polishing system using a magnetostrictive vibrating polisher," Precision Engineering, vol. 37, no. 1, pp. 81-87, 2013.

[6] H. Suzuki, T. Moriwaki, T. Okino, and Y. Ando, "Development of ultrasonic vibration assisted polishing machine for micro aspheric die and mold," CIRP Annals, vol. 55, no. 1, pp. 385-388, 2006.

[7] J. L. González-Santander, R. Fernández, G. Martín, and P. J. Arrazola, "An useful analytical formula to avoid thermal damage in the adaptive control of dry surface grinding," International Journal of Mechanical Sciences, vol. 117, pp. 152-161, 2016.

[8] R. Drazumeric, J. A. Badger, and P. Krajnik, "Wheel lift-off in creep-feed grinding: thermal damage, power surge, chip thickness and optimisation," International Journal of Abrasive Technology, vol. 8, no. 2, p. 97, 2018.

[9] M. Hashish, "A modeling study of metal cutting with abrasive waterjets," Journal of Engineering Materials and Technology, vol. 106, no. 1, pp. 88-100, 1984.

[10] C. Z. Huang, J. Wang, Y. X. Feng, and H. T. Zhu, "Recent development of abrasive water jet machining technology," Key Engineering Materials, vol. 315-316, pp. 396-400, 2006.

[11] Z. W. Liu and R. Y. Liu, "Study on polishing technology for hard-brittle materials by a micro abrasive water jet," Advanced Materials Research, vol. 1027, pp. 52-57, 2014.

[12] J. Wang and W. C. K. Wong, "A study of abrasive waterjet cutting of metallic coated sheet steels," International Journal of Machine Tools and Manufacture, vol. 39, no. 6, pp. 855-870, 1999.

[13] J. L. Cheng, G. Y. Song, and F. Y. LI, "Effects of parameters on the removal rate in abrasive water jet polishing," Journal of Xian institute of Technology, vol. 22, pp. 281-304, 2002.
[14] Y. Wang, H. T. Zhu, C. Z. Huang, J. Wang, and P. Yao, “A study on ultrasonic torsional vibration-assisted abrasive waterjet polishing of ceramic materials," Advanced Materials Research, vol. 1136, pp. 400-405, 2016.

[15] Z. Lv, C. Huang, H. Zhu, J. Wang, Y. Wang, and P. Yao, “A research on ultrasonic-assisted abrasive waterjet polishing of hard-brittle materials," International Journal of Advanced Manufacturing Technology, vol. 78, no. 5-8, pp. 1361-1369, 2015. 


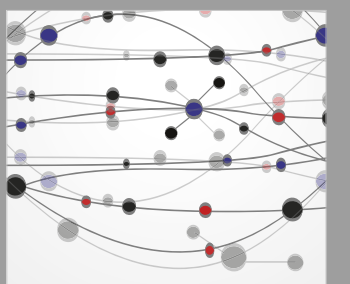

The Scientific World Journal
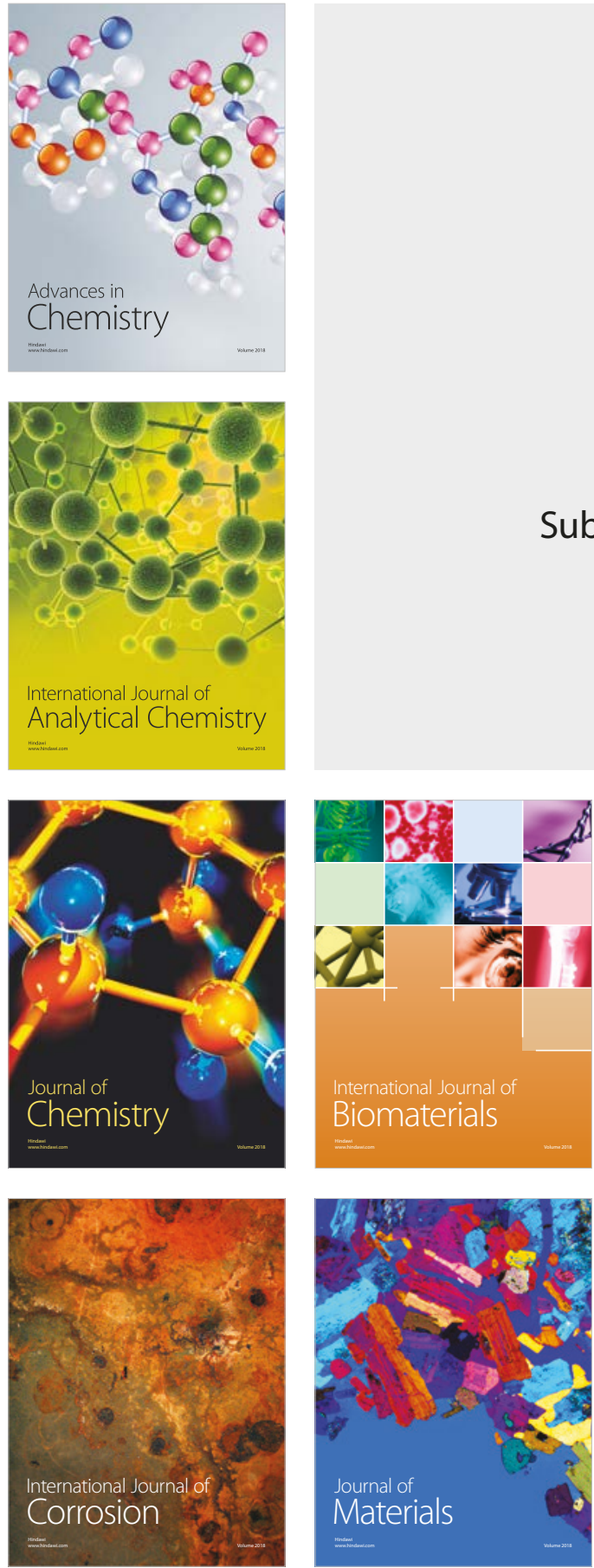

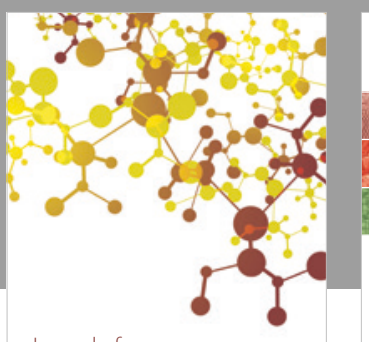

Journal of

Applied Chemistry
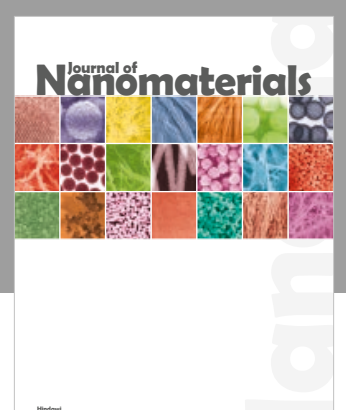

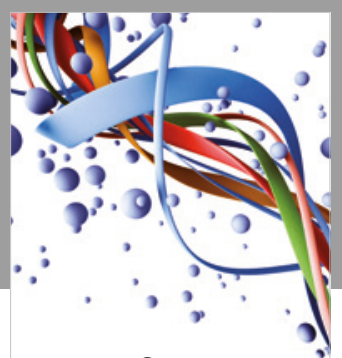

Scientifica

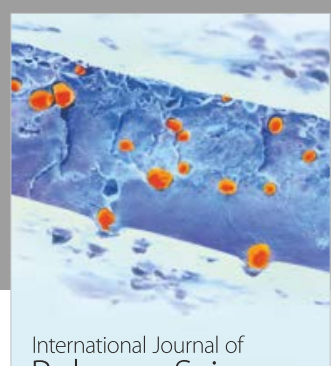

Polymer Science

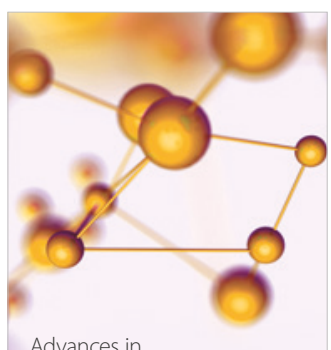

Physical Chemistry
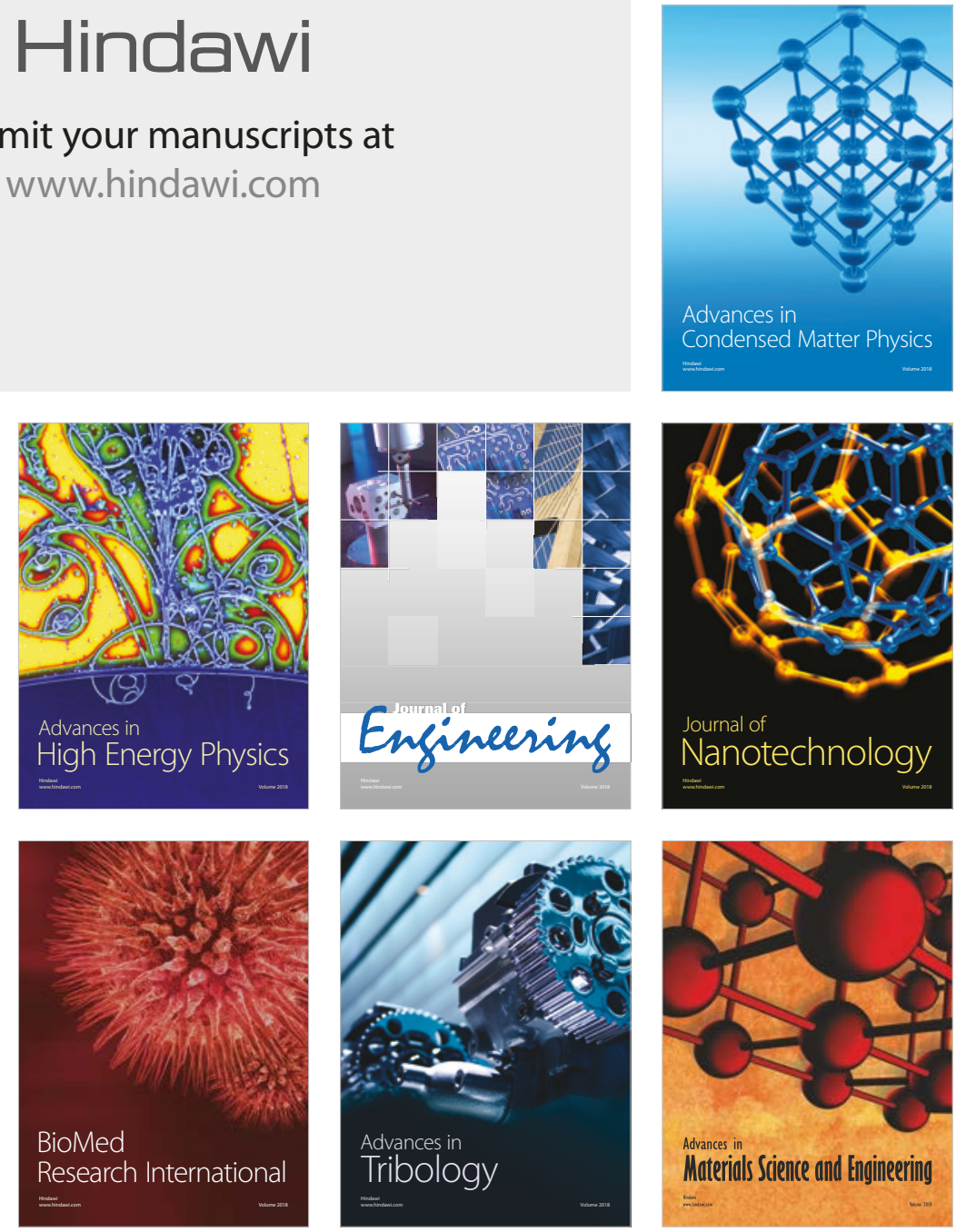